\title{
Research of Radial Forces and Torque of Bearingless Synchronous Machine
}

\author{
Sergei Loginov, Yulia Domracheva, Vadim Smirnov, Dmitriy Fedorov \\ Pskov State University, Electrical Engineering, \\ Department of Electric Drive and Automation Systems. \\ Address: Lenin Square 2, Pskov, 180000, Russian Federation.
}

\begin{abstract}
BSM) is an electrical machine which rotor is suspended by electromagnetic forces (not ball bearings). It allows achieving ultra-high rotation speed and significantly extending area of electric drive application. Nowadays there are different variants of the machines with the structural design and the searching of optimal solution is going on.

The basic calculation parameters of bearingless machines are radial forces that can withstand the rotor from external load and torque produced on the shaft. This article describes the theoretical results based on a computer model that produces the finite element method and experimental study of the BSM prototype.
\end{abstract}

Keywords: bearingless electrical machine, active magnate bearing.

\section{INTRODUCTION}

Electrical machines with active magnetic bearings are used in high-speed motor drives [1]. Implementation of magnetic suspension started being possible by the development of the element base of radio components. As a result, that implementation of complex currents control laws in electrical machines became possible. It enabled the development of new designs of machines, without the difficulties which encountered in the past with limited processing speed signals.

Currently different versions of bearingless electrical machines are being developed, but at the same time each of them has advantages and disadvantages. One of the variants is bearingless electric machine with distributed windings $[2,3,4,5,6]$.

In a bearingless motor gap magnetic field generates both torque and radial forces and it keeps the rotor in the centre. It is a result of electromagnetic field with the help of a drive and a suspension winding superposition $[2,7,8]$. For example motor has a stator with four and two magnetic poles windings and a cylindrical rotor. In figure 1a) is shown magnetic flux $\Phi_{4 \mathrm{a}}$ from drive winding is shown.

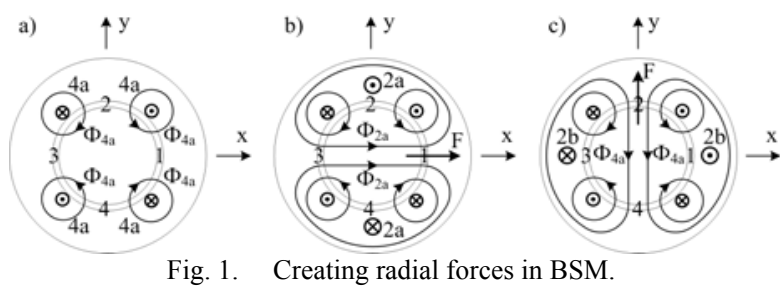

Fluxes create four poles in arias 1,2,3,4. Every pole creates magnetic force, total force equals zero in rotor center position. The principle of radial $x$-force creation is shown in figure $1 \mathrm{~b}$ ). Two poles winding $2 \mathrm{a}$ creates magnetic flux $\Phi_{2 \mathrm{a}}$. Magnetic induction increases in sector 1 as magnetic flux $\Phi_{4 a}$ and $\Phi_{2 a}$ which are summed, and decreases in sector 3 as magnetic flux $\Phi_{4 a}$ и $\Phi_{2 \mathrm{a}}$, are subtracted. So radial xforce appears. The force amplitude is controlled by current in $2 \mathrm{a}$ conductor. Force vector is controlled by current phase. In figure c1) the creation of radial yforce is shown. The principle of 3-phase motor operation is the same $[2,9,10]$.

The basis of this principle allows us to create different types of bearingless motors, such as an induction motor [11], permanent magnet synchronous motor, synchronous reluctance motor, homopolar and hybrid motors [12], switched reluctance motor [13] and etc. Each type of motor has its advantages and disadvantages [14]. In this paper we are going to research on the bearingless synchronous inductor machines [15]. 


\section{MATERIALS AND METHODS}

The creation of an electromagnetic field, that allows hold the rotor in the center position and creates the desired torque are the main goals of control in bearingless machine. Due to the high cost of natural modeling, computer simulation is getting more and more common in the design and study of new devices. Currently there are many computer programs that allow simulate electromagnetic fields in the electrical machines (ANSYS, COMSOL, ELCUT, SolidWorks). Most of them use the finite element method for the analysis. Comparing computer simulation to the analytical description, the apparent advantage of the first one is a higher accuracy that helps to avoid many simplifications. It allows you to explore the model of almost any complexity. Naturally, we cannot speak about the reliability of a computer model of a complex technical device without experimental investigation.

In this paper we present a comparison of the results of computer simulation in the modeling environment FEMM and real modeling of bearingless synchronous machine module. Figure 2 shows a cross-sectional cut of a BSM module with a windings arrangement example.

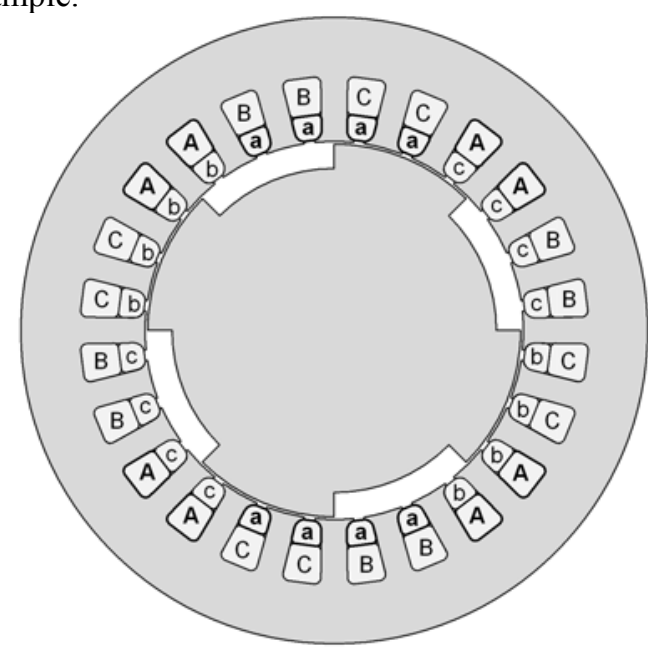

Fig. 2. Module of BSM (A, B, C-drive windings; a, b, csuspension windings).

The rotor module has four poles, as well as one of the stator windings (we call it a drive winding). The second winding (suspension winding) has two poles. Axes of similar phases both of winding drive and suspension winding are the same. The volume occupied by the windings in the slots is determined by the required ratio of the radial force and torque module. The width of the rotor pole is 45 degrees.

The stator of induction motor 4A71B4 is the basis pattern. The stator has 24 slots and two three-phase distributed winding: 4-pole winding drive and 2-pole suspension winding. Winding drive is fundamental, the number of turns in a slot is 50 , and the turn number of the suspension windings is 35 . The length of the rotor's active part is $74 \mathrm{~mm}$.

Figure 3 shows the model modular unit of bearingless electrical machine in the FEMM.

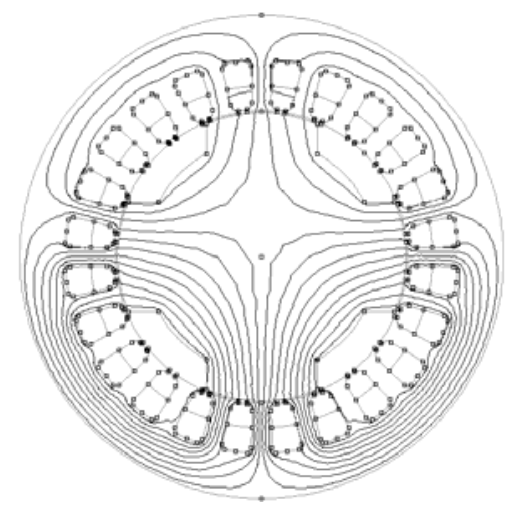

Fig. 3. The model in the FEMM.

The program allows calculating directly the torque and radial forces acting on the rotor.

To create a physical model the stator of the induction motor 4A71B4 was used. The scheme for radial forces research is shown in Figure 4. The rotor has a mechanical support to the ball bearing (point $\mathrm{O}$ ). Assume that this hinge support and the rotor can rotate freely relatively to this point. The load application center of electromagnetic forces $\left(\mathrm{F}_{\mathrm{em}}\right)$ is the center of the stator (point $\mathrm{O}_{1}$ ).

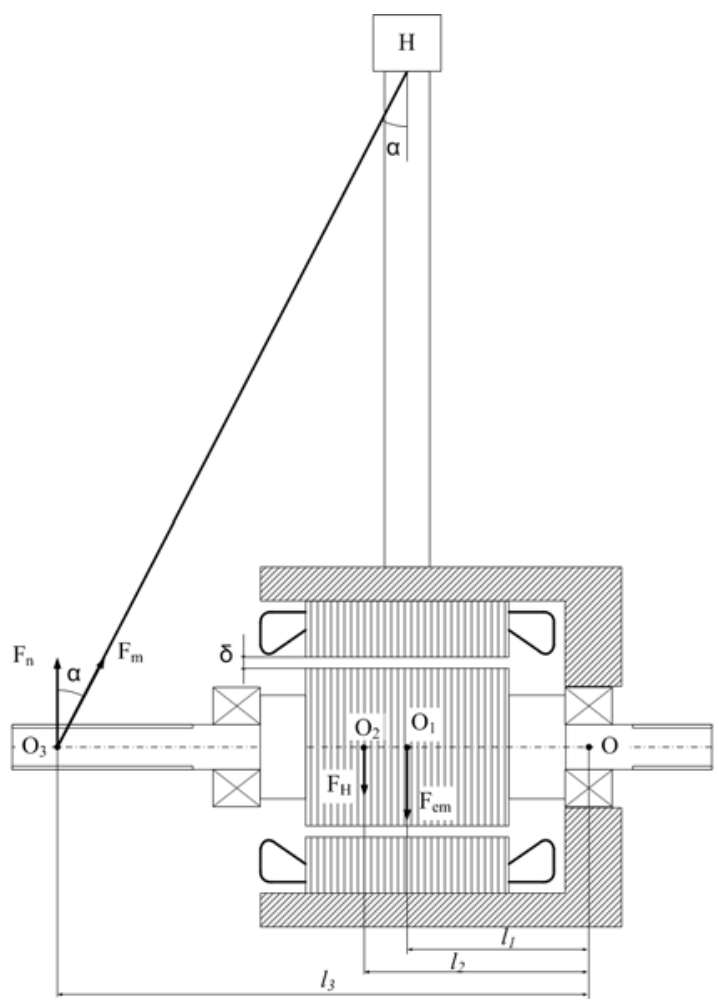

Fig. 4. Scheme for radial forces research . 
The gravity application center $\left(\mathrm{F}_{\mathrm{H}}\right)$ is the rotor mass center - point $\mathrm{O}_{2} \cdot \mathrm{O}_{3}$ - point of balance force application Fm, which is measured by scales.Having known the force $\mathrm{F}_{\mathrm{m}}$ and $\mathrm{F}_{\mathrm{H}}, \mathrm{F}_{\mathrm{em}}$ can be determined.

The moment equation, acting on the rotor relative to point $\mathrm{O}$ is (1):

$$
F_{\text {em }} * l_{1}+F_{H} * l_{2}=F_{n} * l_{3}
$$

where Fn is defined as: $F_{n}=F_{m} * \cos (\alpha)$

So,

$$
F_{e m}=\left(F_{H} * l_{2}-F_{m} * \cos (\alpha) * l_{3}\right) / l_{1}
$$

To find the torque the second ball-bearing was set and the maximum force required to rotate the rotor was measured.

Currents in the drive and suspension windings are delivered from two three-phase inverters and they are measured by ammeters. Currents phases are selected such way that the resulting radial force is directed vertically downward.

\section{RESULTS AND DISCUSSION}

The research purpose is a comparison of the results of a computer simulation and an experiment. The main parameters are the torque and radial force.

During the experimental research only the maximum torque was measured. The torque in this type of machines depends on the angle of rotor rotation relative to the stator field, so the maximum moment angle was determined firstly. The dependence of the torque on the angle of rotor rotation were determined in the FEMM (Fig.5).

For leachate $\mathrm{BOD}_{5}$ is very low, varying from 8.1 to $18.9 \mathrm{mg} / \mathrm{L}$, which is non-typical for young landfill leachate. The reason of this can be landfill management, where concentrate from

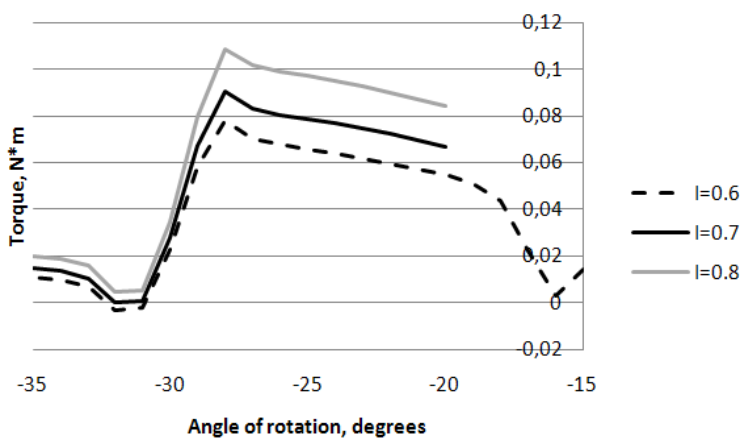

Fig. 5. Torque depending on the angle of rotor rotation 1) $\mathrm{I}_{4}=0.6 \mathrm{~A}$ 2) $\left.\mathrm{I}_{4}=0.7 \mathrm{~A} \mathrm{3}\right) \mathrm{I}_{4}=0.8 \mathrm{~A}$

These graphs are plotted for various values of the drive windings currents. As can be seen, the maximum torque angle does not depend on the value of current and is approximately 28 degrees. The reduction of the date of 17 degrees is explained by the specific situation of the stator teeth from the rotor teeth. Reducing of this impact can be achieved by manufacturing a rotor with beveled slot. In experimental research was obtained the similar data. Thus, all the torque measurements were performed at the rotor rotation angle of 28 degrees.

Values obtained at a suspension windings currents $I_{2}$ are 0 and the changes of drive windings currents $I_{4}$ are shown in the figure 6.

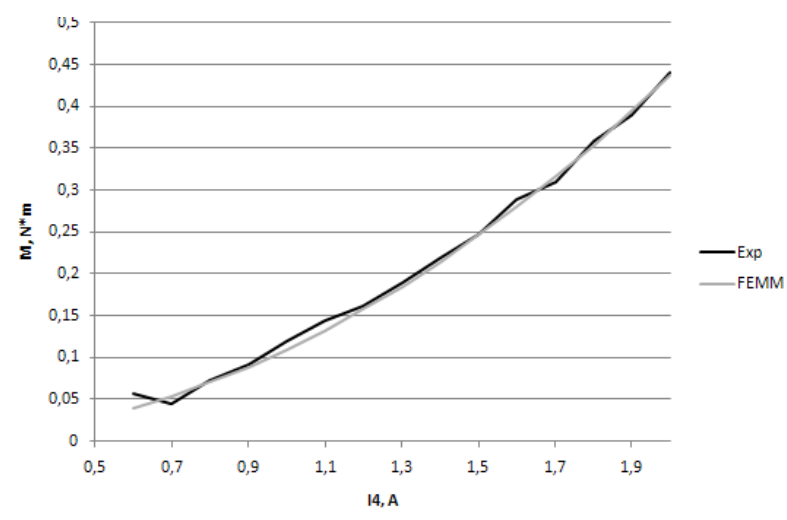

Fig. 6. Torque depending on the drive windings currents.

As can be seen, the results obtained by computer simulation (FEMM) almost completely agree with the experimental research results (Exp).

An important parameter in the bearingless machine is the impact of the suspension windings currents on torque. If this effect is large, the torque on the shaft changes at a constant current $\mathrm{I}_{4}$, which has negative effect on the load. The research of these parameters is shown in the Figure 7.

Date Exp_1 and FEMM_1 is obtained for the drive windings currents $\mathrm{I}_{4}=1$, Exp 2 and FEMM 2 for $\mathrm{I}_{4}=$ 2A.

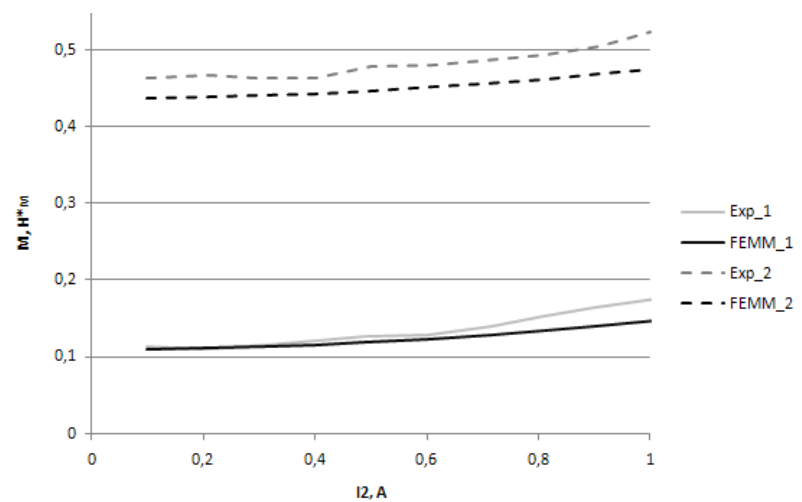

Fig. 7. Effect of the suspension windings currents on the torque.

The discrepancy between the results of computer simulations and experimental research is presented in Table 1. 
TABLE 1 .

THE DISCREPANCY BETWEEN THE RESULTS OF COMPUTER SIMULATIONS AND EXPERIMENTAL RESEARCH

\begin{tabular}{|c|c|c|}
\hline $\begin{array}{c}\text { EXPERIMENT, } \\
\mathrm{N}^{*} \mathrm{M}\end{array}$ & $\begin{array}{c}\text { FEMM, } \\
\mathrm{N}^{*} \mathrm{M}\end{array}$ & $\begin{array}{c}\text { DISCREPANCY, } \\
\%\end{array}$ \\
\hline 0,462 & 0,437 & 5,34 \\
\hline 0,467 & 0,439 & 6,13 \\
\hline 0,462 & 0,440 & 4,72 \\
\hline 0,463 & 0,443 & 4,39 \\
\hline 0,478 & 0,446 & 6,56 \\
\hline 0,480 & 0,451 & 6,12 \\
\hline 0,486 & 0,455 & 6,24 \\
\hline 0,493 & 0,461 & 6,47 \\
\hline 0,504 & 0,468 & 7,11 \\
\hline
\end{tabular}

As can be seen from the table, the difference does not exceed $8 \%$. It can be explained by the assumptions made in the computer model: magnetostrictive saturation and magnetization of ferromagnetic materials are ignore.

Another important parameter for this research is the dependence of the radial forces from the windings currents. Previously it was said that the radial force is generated by magnetic fields superposition generated by the drive and suspension windings currents. Moreover, the radial force is controlled by the suspension windings currents. Therefore, the main thing is the confirmation of the dependence of the radial force of the suspension windings currents. The results obtained by computer simulation (FEMM) and experimental researches are presented in Figure 8.

The dependence of the radial forces from the drive windings currents is also important (Figure 9). Table 2 shows the discrepancy between the results of computer simulations and the experimental research.

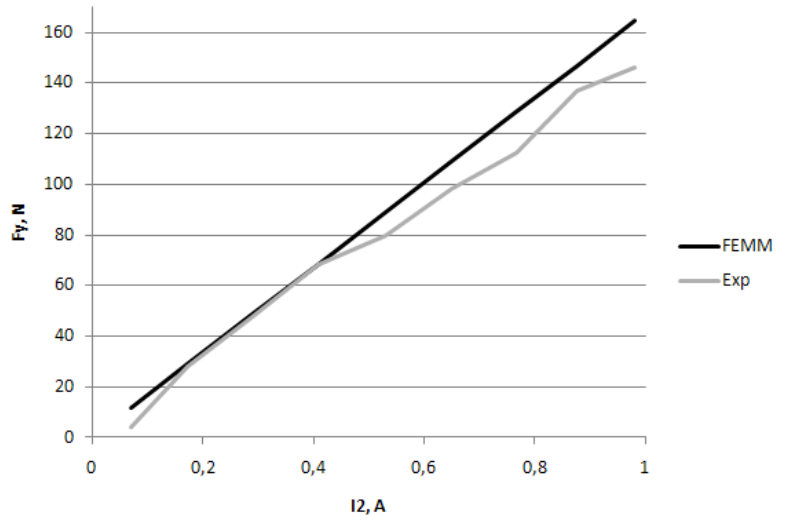

Fig. 8. The dependence of the radial forces on the suspension windings currents.

As seen in the table, the discrepancy does not exceed $15 \%$. Such discrepancy can also be explained by the assumptions made in the computer model.

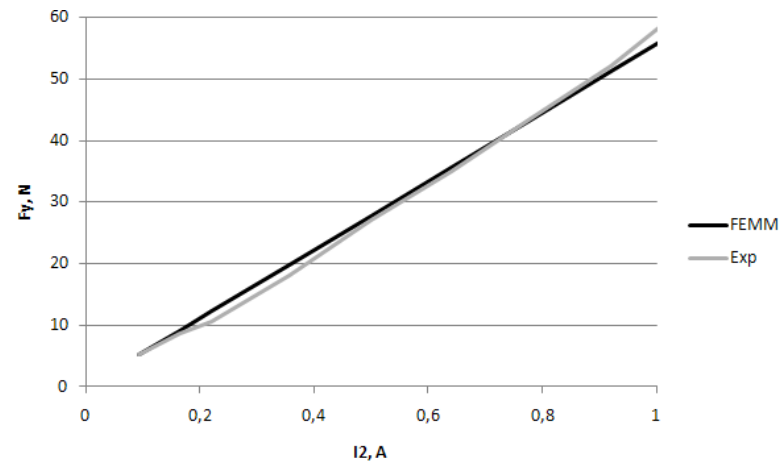

Fig. 9. The dependence of the radial forces on the drive windings currents.

TABLE 2.

THE DISCREPANCY BETWEEN THE RESULTS OF COMPUTER SIMULATIONS AND THE EXPERIMENTAL RESEARCH

\begin{tabular}{|c|c|c|}
\hline $\begin{array}{c}\text { EXPERIMENT, } \\
\mathrm{N}_{\mathrm{M}}\end{array}$ & $\begin{array}{c}\text { FEMM, } \\
\mathrm{N}_{\mathrm{M}}\end{array}$ & $\begin{array}{c}\text { DISCREPANCY, } \\
\%\end{array}$ \\
\hline 28,25 & 29,01 & $-2,69$ \\
\hline 47,81 & 48,55 & $-1,55$ \\
\hline 68,45 & 68,47 & $-0,07$ \\
\hline 79,86 & 88,98 & $-11,41$ \\
\hline 98,33 & 108,9 & $-10,74$ \\
\hline 112,46 & 128,63 & $-14,38$ \\
\hline 136,91 & 146,62 & $-7,09$ \\
\hline 146,14 & 164,42 & $-12,5$ \\
\hline
\end{tabular}

\section{CONCLUSION}

The data obtained in the research demonstrate the adequate usage of the computer simulation technique. Thus, guaranteeing reliable results, computer simulations can be employed to investigate bearingless synchronous machine. Further research are going to be concentrated on the determination of the optimal design of the machine, the study of the dynamic characteristics, the synthesis of control laws and the development of the electronic control unit for BSM.

\section{ACKNOWLEDGMENTS}

The authors would like to thank the Ministry of Education and Science of the Russian Federation for funding this research (Project 403 - "Development of the theory of the bearingless synchronous electric machine").

\section{REFERENCES}

[1] Zhuravlyov Y.N. Active magnetic bearings: theort, design, aplication.St. Petersburg: Politechnica, 2003, pp. 12-25

[2] A.Chiba, T.Fykao, O.Ichikawa, M.Oshima, M.Takemoto, D.G.Dorrell Magnetic Bearings and Bearingsless Drives. /ELSEVIER, pp. 127-135.

[3] A. Chiba, M. A. Rahman and T. Fukao. Radial Force in a Bearingless Reluctance Motor. //IEEE Transactions on IA, 1991, No. 2, pp. 786-790.

[4] A. Chiba, T. Deido, T. Fukao and M. A. Rahman. An Analysis of Bearingless AC Motors. //IEEE Transaction on Energy Conversion, Vol. 9, No. 1, 1994, pp. 61-68. 
[5] A. R. Husain, M. N. Ahmad Deterministic Models of an Active Magnetic Bearing System // Journal of Computers, 2007, No. 8, pp. 9-17

[6] Chen, L. Hofmann, W. Performance Characteristics of one Novel Switched Reluctance Bearingless Motor Drive. // Proc. of Power Conversion Conference (PCC'07), 2007, pp. $608-$ 613.

[7] Katou T., Chiba A., Fukao T. Magnetic suspension force in an induction bearingless motor with a squirrel cage rotor. // Electrical Engineering in Japan, 2007, No. 3, pp. 77-87

[8] Li Chen, Hofmann W. Design procedure of bearingless highspeed switched reluctance motors // Proc. of Internationa Symposium on Power Electronics Electrical Drives Automation and Motion (SPEEDAM), 2010, pp. 1442 - 1447.

[9] Neff M., Barletta N., Schoeb R., Bearingless Centrifuga Pump for Highly Pure Chemicals. //Proc. of 8-th International Symposium on Magnetic Bearings (ISMB 8), Mito, 2002, pp. 283-287.

[10] Bartholet M., Silber S., Nussbaumer T., Kolar J., Performance investigation of two-, three- and four-phase bearingless slice motor configurations, in Power Electronics and Drive
Systems. //Proc. of the 7th International Conference on Power Electronics and Drive Systems, Bangkok, 2007, pp. pp. 9-16.

[11] Loginov S., Domracheva Y. The Model of Induction Bearingless Machine// Proc. of International Conference Low Voltage Electrical Machines, No. 102, 2009, pp. 78-80.

[12] O. Ichikawa, A. Chiba and T. Fukao. Principles and Structures of Homopolar-Type Bearingless Motors. //Proc. of International Power Electronics Conference (IPEC), Tokyo, 2000, pp. 401-406.

[13] Li Chen, Hofmann W. Design procedure of bearingless highspeed switched reluctance motors // Proc. of International Symposium on Power Electronics Electrical Drives Automation and Motion (SPEEDAM), 2010, pp. $1442-1447$.

[14] M. Ohsawa, S. Mori and T. Satoh. Study of the Induction type Bearingless Motor. //Proc. of 7-th International Symposium on Magnetic Bearings (ISMB 7), Zurich, 2000, pp. 389-394.

[15] Domracheva Y., Loginov S. Simulation Technique of Synchronous Reluctance Bearingless Machine // Environment. Technology. Resources. Proceedings of the 9-th International Scientific and Practical Conference, 2013, pp. 101-105. 